\title{
DISCOVERING AND COMMUNICATING THE RATIONALIST ARCHITECTURE OF FORLİ. AN INTEGRATED PROCESS
}

\author{
G. Favaretto ${ }^{1}$, M. Pretelli ${ }^{1}$, A. Zampini ${ }^{1}{ }^{*}$ \\ ${ }^{1}$ Alma Mater Studiorum, University of Bologna, Department of Architecture - (giulia.favaretto2, marco.pretelli, \\ alessia.zampini2)@unibo.it
}

\begin{abstract}
KEY WORDS: Rationalist Architecture, Forlì, Santarelli Kindergarten, Aeronautical College, Foro Boario, Casa del Balilla, ontology, ICT
\end{abstract}

\begin{abstract}
:
A partnership between the Department of Architecture of the University of Bologna and ATRIUM aimed at enhancing the knowledge and communication of the rationalist architecture, built in the city of Forlì during the Fascist regime. The importance of finding an interpretative key for this dissonant heritage, bearers of an "uncomfortable" memory but at the same time able to strongly characterize the architectural quality of cities, was a primary goal.

The cooperation started with the development of a pilot project regarding three architectures considered iconic for this context but also able to foster more complex urban policies. The first deliverable of the programme was the search, record, and management of the archival materials related to the whole history of these buildings. The enormous amount of data acquired revealed the importance of working on a dual track, aimed at both the stakeholders involved in the management process of this heritage and those who experience it.

For what concerns the "technical level" which is related to the knowledge field, the first challenge was to understand how to manage information boosting interoperability, guaranteeing easy access and above all making the research implementable. According to the "touristic level" instead, a further objective of the project was related to the communication of this heritage to a varied audience of visitors.
\end{abstract}

\section{INTRODUCTION}

The construction of models useful for managing the protection and restoration of the architectural heritage is at least a century old theorization (Riegl, 1903).

Until recently, these models were only limited to the realization and organization of graphic models, however articulated and elaborate they may have been. Exemplary in this regard is the contribution provided by the Normal Commission on the topic "representation of the degradation forms" since the 80s of the last century, as it has always represented one of the main focus of the disciplinary thought.

Today, on the contrary, the use of increasingly advanced data collection and management techniques opens new horizons, partially unexplored.

The heritage protection cannot and must not be seen as detached from its enhancement (Italian Legislative Decree 42/2004, art. 6, art. 11 et seq.). Among the core activities of this conjunction, those aiming at making the inner meanings explicit, at fostering the knowledge and awareness in a broader touristic sense - even if touristic is not exhaustive in this case are certainly some of the more important.

The undertaken activities described in this contribution try to bond all the abovementioned aspects, and according to them, deal with the following features:

- the meticulous method of recording a documentation rich of extremely uneven data and information, over very long time intervals;
- the consequent necessity of developing an ontology, able to guarantee an efficient use of this amount of information, as the Local Administration commissioned this work with a view to future restorations. The several databases produced at national level collect millions of gigabytes of data with any concrete effect on the real world, excepting for the cataloguing activities that could be considered praiseworthy but sterile, and this is due to the difficulties of finding the right information in reasonable times;

- the definition of multileveled matrixes for the interpretation of data, aspiring at contributing to the touristic enrichment and professional improvement promoted by the Local Administration in association with other institutions, including the University; but also aiming at the repossession of a long-neglected and denied heritage by local communities (De Varine, 2005).

All this finds, in the possibility of constructing models of interpretation and management of data, an effectiveness, which, it is hoped, will be able to offer an active contribution in favouring more successful protection of the built heritage, in this case, constituted by the rationalist architecture of Forlì.

According to these aspirations, in 2015, the Department of Architecture of the University of Bologna signed an agreement with ATRIUM - Architecture of Totalitarian Regimes of the XX Century in Europe's Urban Memory, a cultural route of the Council of Europe that supports the preservation of this "dissonant" architectural heritage. Aware of the importance of

* Corresponding author 
finding an interpretative key for these objects, bearers of an "uncomfortable" memory the cooperation started with the development of a pilot project regarding three architectures considered iconic for this context but also able to foster more complex urban policies. The choice was on buildings whose preservation was jeopardized by the abandon or the lack of maintenance: the former Santarelli kindergarten, the former Aeronautical College and a former cattle market known as Foro Boario.

[MP]

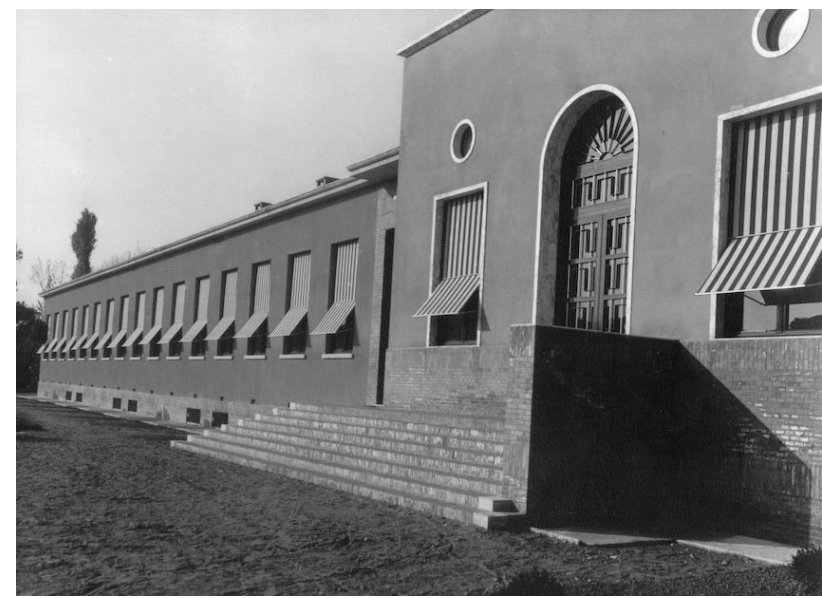

Figure 1. Santarelli kindergarten. () Biblioteca Comunale "Aurelio Saffi” di Forlì, Archivio Santarelli, album fotografico 2 “Asilo Infantile 'Santarelli’ Forlì.

\section{THE IMPORTANCE OF HERITAGE INFORMATION}

According to a definition provided by Letellier, the process of Heritage Information involves all those "integrated activities of recording, documentation and information management", required to "acquire knowledge, understand meaning and values, promote the interest and involvement of people" (Letellier, 2017). A statement that correctly resumes the assumptions underlying the project of enhancement of the Architecture Heritage built in Forlì during the Fascist era.

The project aimed at two kinds of purposes: the very first was to provide local administration with an accurate operative tool for the planned and preventive conservation of this dissonant heritage. The second one was to identify the proper way and the appropriate tools to let this knowledge transferable to other specialized tourists/actors, in particular architects, engineers or restorers.

The paths established, apparently very divergent for expected outputs and results, started instead from the same cultural activity, which consisted precisely of recording and managing the documentation regarding the whole lifecycle of the three buildings selected: the former Santarelli kindergarten (Figure 1), the former Aeronautical College (Figure 2), Foro Boario (Figure 3). This process of research, acquisition, and organisation of data should be integrated into the entire conservation process, from its preliminary stages for continuing even after the completion of the intervention (Whalen, 2017).

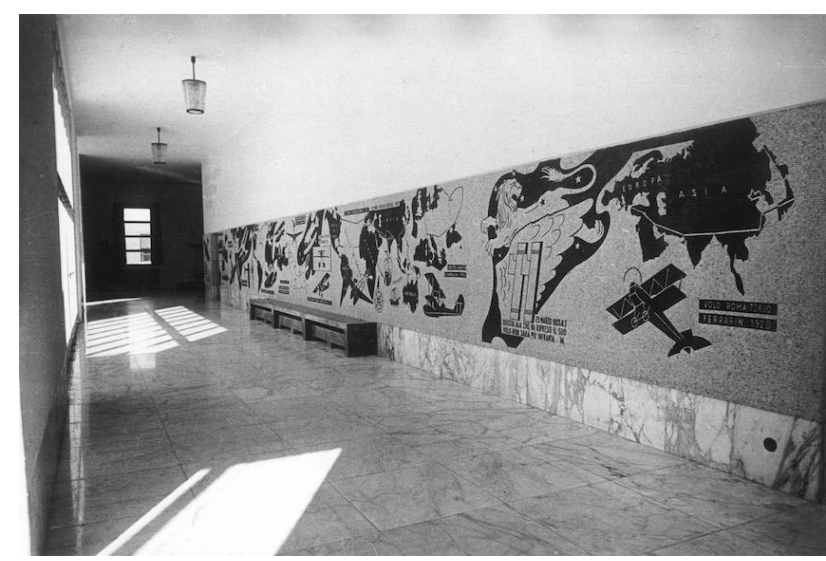

Figure 2. Former Aeronautical College. Mosaics. (A) Archivio Valle, Roma, scatola 26, CV-FOT/061

The challenge to testify the whole history of these three case studies thanks to the archival documentation immediately revealed as a vast and complex task to carry out. These architectures had a relatively brief history is compared to other kinds of buildings, though the research presented some significant critical as the lack of comparable studies, producer or collectors subjects spread all along the Italian territory and sometimes neither so easy to detect, non-inventoried archival fonds that had never investigated before or fonds partially destroyed by war. Despite all this, the research produced and digitalized about 25.000 documents, most of which were unpublished

When completed the threads of research, how to manage this amount of information and above all giving the keys to simplifying the access to them, to foster their use and comprehension instead of discouraging it, become the primary objective to pursue.

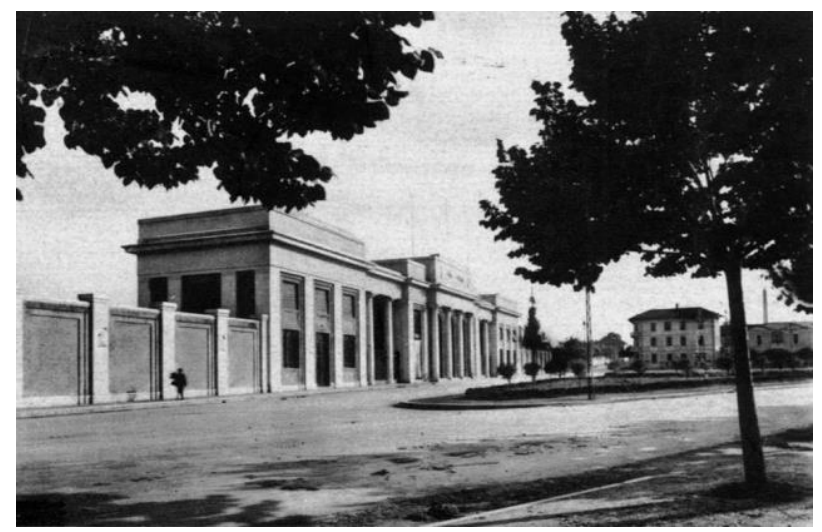

Figure 3. Foro Boario. http://www.spaziindecisi.it/new/wpcontent/uploads/2014/05/Foro-Boario.jpg

\subsection{The definition of an ontology}

The necessity to accomplish the examination of these materials according to an analytic approach and the application of a critical appraisal for their interpretation, led to the decision to order them according to the classes, properties and relationships proper of ontology, as to say a categorical knowledge about "possible states of affairs" (Guarino, 1998)

Among the ontologies for Cultural Heritage, which find in the CIDOC-Conceptual Reference Module their forerunner and 
common basis (Doerr, 2003), the analysis of the state of the art acknowledged the presence of previous research aimed at establishing an ontology-based framework for modelling architectural knowledge (Acierno et al., 2017).

According to this study, the semantic domains referring to architecture are four: the artefact, its lifecycle, the investigation process and the actors involved, each connected to others thanks to specific relationships.

In order to describe the artefact, twofold classes are established: spatial and constructional, both based on four breakdown levels. The constructional classes, being based on a technological approach, revealed to be the most appropriate to manage the first stage of categorization of the information registered for the three Rationalist architectures, even if some modification and integration were required.

According to the named ontology model, the constructive classes of a building consists of construction unities - namely covering, floors, elevations structures and foundation - in turn made of construction components divided as follow: communication (staircase, doors and windows), vertical (wall, pillars, columns, ...) and horizontal (load-bearing and not load bearing). Each component is then split into constructive elements, simple or complex (masonry, plasters,...) made of constructive materials (brick, sand, lime, concrete,...) (Acierno et al., 2017).

The classes and subclasses here presented are equivalent to those established by the Guidelines for the planned and preventive conservation of the Architectural Heritage (Della Torre, 2002) even if it is possible to appreciate some modification in the hierarchy. Here the classes/elements proposed are the following: foundation, vertical structures, horizontal structures, coverings, vertical connection, outdoor pavements, indoor pavements, interior decorations, exterior decorations, outer coverings, exterior coverings, interior fixtures; exterior fixtures and plants.Both the systems refer to the 1981 norm UNI 8290-81 but represent an update that best suits the need of the project for Forlì as they allow a degree of sophistication sufficient to describe the work in detail, but such as not to be too meticulous and punctilious. Nevertheless, all of them ignored furniture, on the contrary, it was a significant feature for the history of these buildings because it was often customized and it represented a witness of the technical ability of the time.Moreover, other kinds of documents have been found regarding not only the material essence of the building but also their general history. Records that could be interesting, above all, to enrich the narrative levels, or to better understand the cultural context in which these buildings were erected.

Due to these observations, the constructive classes were rearranged in the following two levels, corresponding to the construction unity level established by (Acierno et al., 2017), with the addition of two classes:

$$
\begin{aligned}
& \text { General history } \\
& \text { Structures } \\
& \text { - } \quad \text { Foundations } \\
& \text { - } \quad \text { Vertical structures } \\
& \text { - } \text { Horizontal structures } \\
& \text { - } \quad \text { Coverings } \\
& \text { - Vertical connection } \\
& \text { Finishings } \\
& \text { - Pavements } \\
& \text { - Decorations } \\
& \text { - } \quad \text { Fixtures }
\end{aligned}
$$

Plants

Furniture

Exterior arrangement

\subsection{Applying the ontology}

Before the ontology application, a step back is essential, requiring a clarification regarding the kind of documents detected and their order in the various archives.

The fond scanned belonged to several actors, involved in the same work in different terms. In addition to that, the conservative event of the archives returned a chaotic organization of some folders (the State Archive of Forlì and the Historical Archive of the region Emilia Romagna have suffered damage during the Second World War). Thus, the first step or rearrangement broke the inner archival links aiming at structuring the data according to the intervention of reference.

When describing the characteristics of ontologies for Cultural Heritage, it has been pinpointed how the information could be considered event-centric: "things, peoples and ideas connect and relate via events" (Doerr, 2009). So this is exactly the chosen approach: structuring the information on the base of the 'events' characterizing the whole lifecycle of a building, as to say the groups of single works and commitment sharing the same goals in a coherent period.

All the digitalized copies were, therefore, first of all, stored in digital folders corresponding to these unitary interventions, giving the opportunity to build up a chronologically ordered database (1).

In order to make an example of this digital relocation, it is useful to examine the folder referring to the "Construction of the former Santarelli kindergarten". Labelled with the period 1934-1937, it establishes clear relationships of 'before' and 'after' concerning all other folders, but it has a very complex structure. Documents coming from the Municipal Library of Forlì, from the historical archives of the City Council and of the Technical Office physically conserved at the State Archive in Forlì and from the Dux's Special Secretariat stored in the National Archive in Rome concurred to its formation. The original provenience of the documents is, in any case, documented and respected as several digital sub-folders correspond to specific archival folders. The relationship instead is made explicit thanks to the use of a Microsoft Excel spreadsheet (2).

In addition to that, in each subfolder, the documents have been identified according to their type (report, estimates, call for tenders, invoices, lists of workers, lists of works, booklets of measures, tables, photographs, ...)

Once completed the chronological organization, the ontology has been applied, and each group of documents has been tagged as belonging to one or more classes or sub-classes. Working in macOS environment, the tags were directly applied to folders,

1 Currently, the database is conserved on a portable storage device and it has been transferred to the internal server of the ATRIUM association, but it has not been developed a digital framework able to guarantee its online fruition. The accessibility is allowed only to scholars who request it and who physically go to the headquarters of the association.

2 The use of this kind of software is due to the fact that guaranteeing an extensive use of this material, preventing the acquisition of specific skills was a priority, not only a desideratum expressed by the institutions. A Microsoft Excel file, moreover, is compatible with other open source software and this enlarges, even more, the possibilities of fruition of this database. 
but to transfer this information to Microsoft user, the tags have also been reported in the Excel file.

A simple matrix has been established, each line corresponds to one folder (and therefore to one intervention) while columns are dedicated to: Date, Description of intervention, Archival signature (Archive, fond, folder), Tag (Figure 4)

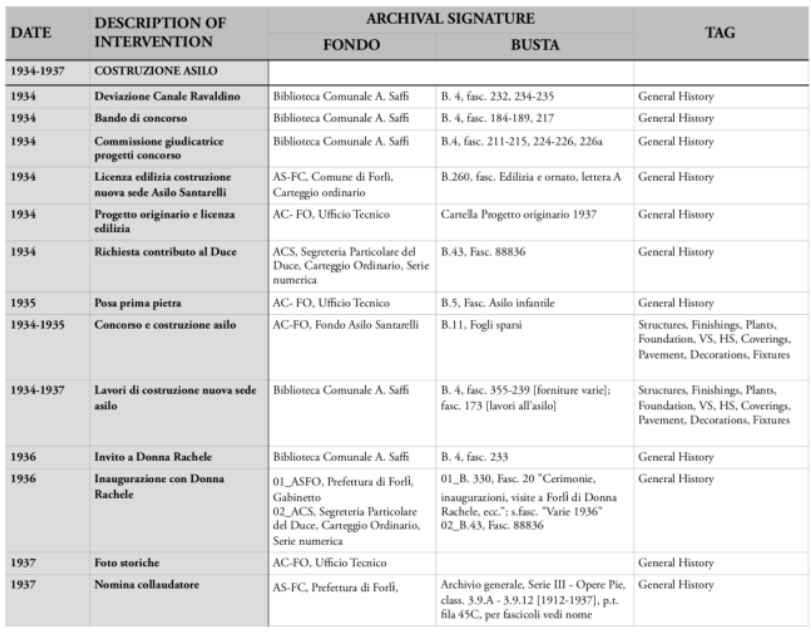

Figure 4. Santarelli kindergarten. Matrix extrapolated from the Excel file regarding the folder 1934-1937 "Construction of the building" with the archival signature and the assigned tags.

Thanks to this work it has been possible to gain a very detailed twofold historical regest. On the one hand, it is possible to see all the intervention carried out on the building, during the whole lifecycle, in chronological order, knowing which parts they affected. On the other hand, it is possible to know for example in which years the intervention regarding the plants has been completed or also if the reconstruction in the aftermath of World II concerned the roof or not. Furthermore, opening the related folder, it is possible to read all the single documents.

The activity of information management stopped at this hierarchic level. Considering the time available, it was evaluated the most appropriate for answering the Administration and Association's current requirements. However, further specific in-depth researches have been conducted in order to test both the storage and search tool system.

Restoration works will soon begin on the former Santarelli kindergarten, and the external plasters will be subject to some transformations. Since this is a delicate subject as very rare and fine plasters known as 'Terranova' had been used here, a specific tag has been assigned to all the documents concerning the execution and transformation of this material. This tag indeed refers to the 'constructive material' and this level is not involved in the executed classification. Despite that, the search for these specific documents has been speeded up and simplified thanks to this preliminary operation, and this is the demonstration of how effective the system could be.

\subsection{Possible future developments}

The proposed ontology represents a "flexible hermeneutical process open to new developments" (Fiorani, 2017) It is also interesting to notice how this architecture of data, if developed till the subsequent level of constructive elements could easily aliment the future development of an HBIM that will become compulsory for the management of buildings belonging to the Public Administrations.

A further step into the materials level will be useful instead in order to make transversal research regarding their use and restoration. This specific contents, together with the documents related to the (good or bad) solutions employed, could be transformed into food for thought, building up technical handbook for architects, engineer or restorers involved in the restoration process of the architectures built during this peculiar period.

Having applied the ontology here described has therefore revealed a key role for the management of the information and documents recorded - and to register in the future - Thanks to this formal, shared and explicit descriptions of data, the results of the investigation can be effectively used for planning the conservation. A powerful and useful instrument has been provided for supporting decision making.

Moreover, the contents gathered here and thus organized become a fundamental basis for structuring an educational path oriented to develop the potentials of cultural tourism. [AZ]

\section{THE CULTURAL TOURISM: KNOWLEDGE IS BEAUTIFUL!}

The second dissemination level that has been considered by the agreement between the Department of Architecture of the University of Bologna and the ATRIUM Association concerns cultural tourism.

As a matter of fact, the research carried out has been developed in order to achieve a double and complementary objective. On the one hand, the discovery of a huge amount of archival material was accompanied by the retrieval of bibliographical sources relating to the buildings under investigation, as well as by the orderly collection of photographs taken on site: the digitalisation and ontological reorganisation of this extended documentation allowed to provide useful materials for the determination of future restoration projects. On the other hand, the aim was to study strategies capable of activating participatory and attractive processes: the diffusion of awareness of the value of the rationalist architecture in Forlì is part of a broader project aimed at enhancing the 20th century heritage of the city. After all, if it is true that buildings beauty belongs to everyone (Hugo, 1993 [1825]), it is equally true that stimulating society by making mute things speak (Febvre, 1966) brings citizens closer to heritage.

Starting from the early developments of the Por Fesr (that stands for the regional operational programme of the European regional development fund) 2014-2020, participation and attraction have taken on progressive relevance. Within this programme, the priority axis 6 about the "attractive and participatory towns" contributes to the implementation of the European Urban Agenda in Emilia-Romagna. In this perspective, a regional network of cultural attractors has begun to shape: 10 open workshops, linked to specific themes, are about to be realised in this region of Italy. In Forlì, the municipal administration, together with ATRIUM, has chosen the Santarelli Kindergarten as the asset where to develop the abovementioned project. Especially, in this specific case, the 
open workshop is dedicated to the theme "cultural heritage and active citizenship"3.

In practice, the Santarelli Kindergarten constitutes a component of a wider path of enhancement. Indeed, the intent is to implement strategies of cultural tourism aimed at telling the emblematic history of Forlì in the period between the two world wars. Multiple initiatives have already been realised in this city of Romagna. The editions of the Festival "Forlì city of the 20th century" have organised exhibitions, shows, seminars and guided tours. Furthermore, public meetings have made it possible to explain the ongoing project, not only to inform citizens but also to identify shared solutions. The following steps concern the implementation of an open-air museum of the 20th century in Forlì.

At this point, technicians gravitating around restoration come back into play. As a matter of fact, this project may also represent an opportunity for the professional growth of designers and operators. In this regard, the calibration of the open-air museum routes on different architectural levels of detail allows both to attract common citizens and to provide useful data and information to professionals.

Especially, the Information and Communication Technologies play a central role in this project aimed at enhancing Forlì as an emblematic city of the 20th century.

\subsection{Disseminating the project}

The first step in implementing a virtuous process of cultural tourism in Forlì concerns the dissemination of the project. In this perspective, the web constitutes a useful tool for attracting not only the inhabitants of Forlì but also citizens from farthest away. Moreover, as has already been mentioned above, a particular appeal is addressed to professionals.

A first moment of knowledge about the themes related to the 20th century tangible and intangible heritage in Forlì is already possible thanks to some websites, such as those of ATRIUM (4), Resistenza mAPPe (5) and Spazi Indecisi (6).

After these experiences, the will is to construct an internet portal specifically dedicated to the open-air museum of Forlì. Focused on the 20th century heritage of the city, it is aimed at disseminating the project underway. Indeed, people will be able to connect remotely to this internet portal and to access a series of information.

Reached the website, a first focus could be dedicated to a summary of the main historical events that have made Forlì an emblem of the mutation in the Fascist period. The second level of detail could explain the project of the open-air museum of the 20th century in Forlì. A third passage could anticipate the possibility of taking narrative and descriptive itineraries through the streets and inside buildings of the city. Finally, a fourth step could be dedicated to some basic information (such as the building's author, the period of realisation and the main events

3 http://fesr.regione.emilia-romagna.it/erdf/axis/attractiveparticipative-towns-2013-axis-6 (14 March 2019).

4 http://www.atrium-see.eu; http://www.atriumroute.eu; http://atrium.comune.forli.fc.it (14 March 2019).

5 http://resistenzamappe.it/forli (14 March 2019).

6 https://www.spaziindecisi.it (14 March 2019). and transformations) about the architectures along the routes. More in-depth information should then be provided in loco.

\subsection{Walking through the streets of the city}

The first moment of knowledge, which will be possible remotely, could be followed by the visit of the open-air museum of the 20th century in Forlì. Effectively, it will take place through the streets of the city.

Depending on interest, visitors will have the opportunity to take several routes which will be linked to red threads. In order to achieve this objective, specific instrumentation will be needed: on the one hand, some devices, including wearable ones, may be rented in Forlì; on the other hand, private mobile devices, such as smartphones or tablets, that will have to download a specific app, may be used. After connecting to the virtual system set up in the city, it will be possible to view several mapped routes and to undertake the visit of the museum through the streets of Forlì. Individuals will be able to go down the roads autonomously or with guided tours, which will, in turn, be calibrated on the basis of the users: there will be visits for both common citizens and professionals working in the field of architecture and restoration.

Following the several itineraries, it will be possible to reach staging points equipped with hotspots. Close to rationalist architectures, near buildings that have been transformed during the Fascist period or in strategic points of the city, QR Codes or Beacon technology based on Bluetooth may be intercepted. Therefore, useful connections may be established: in this way, the devices in possession of visitors will be able to access digitalised materials, such as drawings, historical photographs, videos of Istituto Luce, audio reproductions and written documents. These materials will allow the description of significant events relating to emblematic urban areas that are linked to the development of Forlì during the Fascist period, as well as the descriptive introduction of individual architectures.

\subsection{Knowing buildings and their histories}

The possibility of deepening the historical and constructive events of the buildings along itineraries will materialise inside the architectures. Within these buildings, the logic of presentation of the materials is similar to the abovementioned one; the difference is in the level of detail.

As a matter of fact, inside the rooms of the architectures, there will be the possibility of starting connections to view design drawings or historical photographs of the spaces, to follow videos of significant events related to the building, to listen to evocative sounds, as well as to read selected written documents. In this regard, materials organisation according to specific themes will allow the user to choose which aspects to deepen. Furthermore, the use of electronic devices may be implemented by the augmented reality in order to enhance immersion in the events which have led to the current consistency of the several architectures.

Within the framework of this project which is in fieri, the first buildings that will be set up to present the abovementioned documentation will be two emblematic architectures: the Santarelli Kindergarten, that has been abandoned since 2012 and that today is waiting for the start of the restoration works, and the Casa del Balilla, which has recently been restored.

Narrating the history of rationalist architectures in Forlì allows strengthening the awareness of existing heritage relevance as a material document. At the same time, implementing routes of 
cultural tourism involving professionals helps increase the skills of those who work in this special field.

\subsection{The Santarelli Kindergarten and the Casa del Balilla: architectures with key roles in Forlì}

The Santarelli Kindergarten and the Casa del Balilla will constitute strategic hubs of the project concerning the open-air museum of the 20th century in Forlì.

As has already been mentioned above, the restoration intervention at the Santarelli Kindergarten is about to be started. Regarding material consistency, the hope is that documents that have been found can help to maximise the conservation of the existing matter. Regarding reuse strategies, complementary spaces will be established inside the building. According to the new functional organisation, there will be three main cores: the library, the interpretation centre and the innovation lab. In these spaces, the Information and Communication Technologies will be essential tools for the achievement of specific objectives.

The library in the Santarelli Kindergarten will be the complementary reality of the already existing municipal library which is located in the Palazzo del Merenda. This 18th century building will continue to host the bibliographic collection of the Municipality of Forlì, while the Santarelli Kindergarten will bring together 20th century materials. Moreover, digitalisation processes will allow realising an archive here available.

The interpretation centre will constitute a coordination point: it will welcome visitors and provide more detailed information on the possible routes in the city. Nevertheless, it will propose different reading keys linked to several itineraries. Projections, multimedia tools, keywords and some explanations will orient users towards the choice of the routes to be followed.

Finally, the innovation lab will be the headquarters of the technology company which has been delegated for the development of the abovementioned applications. On the one hand, the agreement between the Department of Architecture of the University of Bologna and the ATRIUM Association led to the carrying out of research aimed at finding materials related to some significant 20th century architectures in Forlì. On the other hand, the technology company based in the Santarelli Kindergarten (Figure 5) was entrusted with the transposition into a multimedia language of the discovered and selected material. Teamwork will therefore be essential to make these two fronts dialogue.

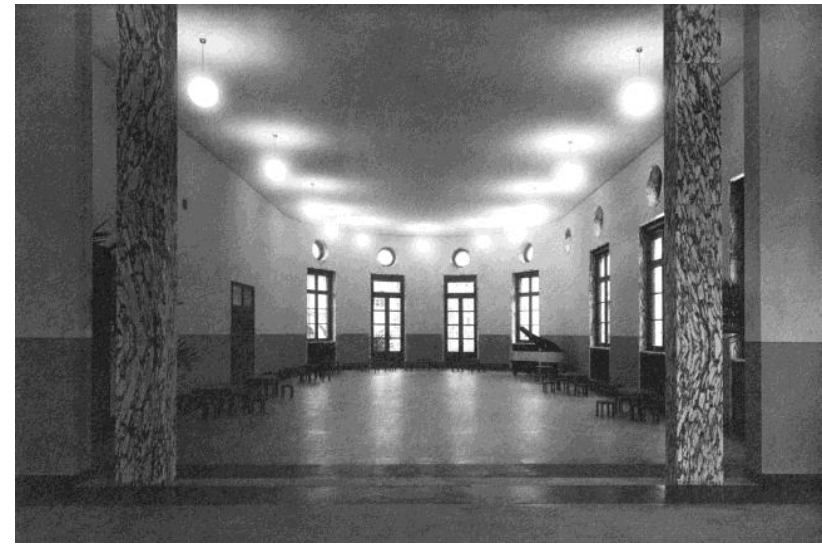

Figure 5. Santarelli Kindergarten, internal view of the period. ()

Biblioteca Comunale "Aurelio Saffi" di Forlì, Archivio

Santarelli, album fotografico 2 "Asilo Infantile 'Santarelli'

Forlì. Esterni ed interni del locale inaugurato nel novembre

1936", 19.
Furthermore, the setting up of the Santarelli Kindergarten will allow the narration of its main historical and constructive events. From here, the routes in the city can then branch out. Nevertheless, the visit path of the open-air museum will have an additional starting point: the Casa del Balilla (Figure 6). Located along the railway station boulevard, the building is the legal address of ATRIUM. From here, the guided tours will be able to start.

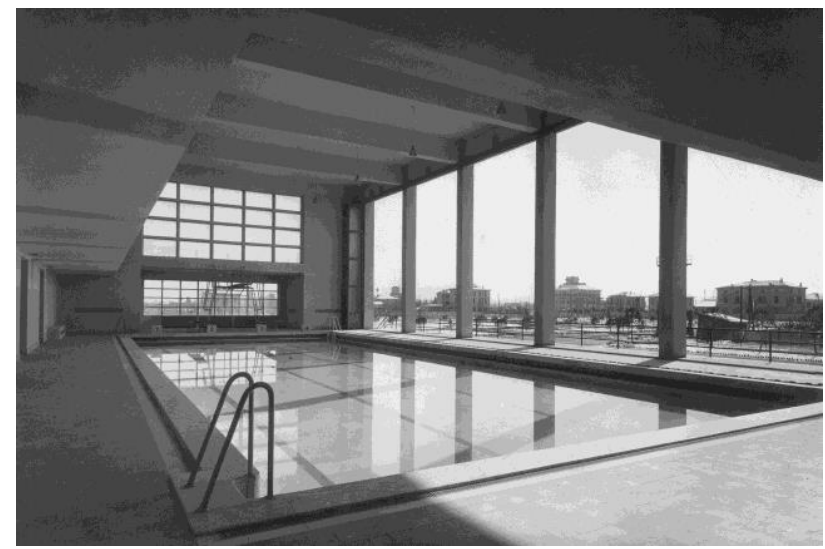

Figure 6. Casa del Balilla, internal view of the period. ()

Archivio Cesare Valle - Roma, Fotografie, scatola 25, CVFOT/039.

The hope is that installations inside buildings may progressively extend to other architectures. In this way, the historical events and constructive aspects of more and more 20th century buildings in Forlì could be better known along the routes of this city of Romagna. Cultural tourism is expected because knowledge is beautiful!

[GF]

\section{CONCLUSIONS}

Protection is a complex activity, consisting of a wide range of actions. Only a few of them are exercised directly on the physicality of the concerned assets.

It starts from the activities aimed at obtaining their in-depth knowledge, a permanent pursuit, which can never be considered totally completed, being indissolubly linked to their entire lifecycle.

It ends, only temporarily, with the definition of the restoration project (where the state of conservation requires it) and the subsequently scheduled maintenance practices. At the same time, it is made up of all those articulated and organically coordinated, actions of enhancement aimed at publicizing this heritage and making it appreciated by the whole society - from the local community to the community of enthusiasts and technicians; this being an indispensable factor in ensuring the fundraising required for the protection policies. [MP]

\section{REFERENCES}

De Varine, H., 20015. Radici del futuro. Il patrimonio culturale al servizio dello sviluppo locale. CLUEB, Bologna.

Della Torre, T., 2012. La conservazione programmata del patrimonio storico architettonico. Linee guida per il piano di manutenzione e il consuntivo. Edizioni Angelo Guerini e Associati, Milano. 
Doerr, M., 2003. The CIDOC Conceptual Reference Module. An Ontological Approach to Semantic Interoperability of Metadata. AI Magazine, 24(3), 75-92

Doerr, M., 2009. Ontologies for Cultural Heritage. In: Staab, S., Studer R. (eds) Handbook on Ontologies. International Handbooks on Information Systems. Springer, Berlin, Heidelberg. doi.org/10.1007/978-3-540-92673-3_21

Favaretto, G., Pretelli, M., 2018. ATRIUM: the cultural route and the heritage of Forlì, in Porfyriou, H., Yu, B., (eds.), China and Italy: routes of culture, valorisation and management. CNR Edizioni, Roma, 61-71.

Favaretto, G., Pretelli, M., Signorelli, L., 2017. Il valore del patrimonio, l'identità del "paesaggio", l'attrattività culturale: studi per la valorizzazione dell'architettura razionalista a "Forlì città del Novecento", in Belli, G., Capano, F., Pascariello, M.I., La città, il viaggio, il turismo. Percezione, produzione e trasformazione, CIRICE, Napoli, 2899-2905.

Febvre, L., 1966. Problemi di metodo storico. Einaudi, Torino, 177.

Fiorani, D., 2017. La modellazione della conoscenza nel restauro: uno sviluppo per BHIMM. Problematiche generali e il caso-studio di San Saba in Roma, in Della Torre, S., (ed) Built Heritage Information Modelling/Management BHIMM, sistema editoriale Ingenio, https://www.ingenioweb.it/Sfogliabile/ReportageBHIMM2017 (Last accessed on March 2019)

Grimaldi, M., Natale, M. T., 2016. Quando le app sono al servizio del patrimonio culturale. Digitalia, 70-90.

Guarino, N., 1998. Formal ontology in Information systems. In: Guarino, N. (ed), Formal ontology in Information systems. IOS, Amsterdam, 3-15.

Hugo, V., 1993 [1825]. Guerra ai demolitori! Stampa Alternativa, Roma, 8.

Irace, F., Ciagà, G. L., Lupo, E., Trocchianesi, R., 2013. Design \& cultural heritage. Electa, Milano.

Letellier, R., Schmid, W., LeBlanc, F., 2007. Recording, Documentation, and Information Management for the Conservation of Heritage Places: Guiding Principles. Getty Conservation Institute, Los Angeles, CA, http://hdl.handle.net/10020/gci_pubs/recordim Consulted March 14, 2019.

Riegl, A. 1903. Der Moderne Denkmalkultus. Sein Wesen un Sein Entstehung, K.K . Zentral-Kommision für Kunst- und historische Denkmale, Wien, 1903 